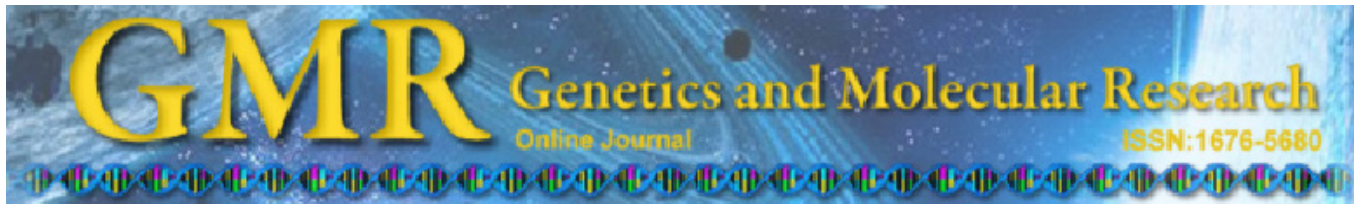

\title{
Major quality trait analysis and QTL detection in hexaploid wheat in humid rain-fed agriculture
}

\author{
H.M. Li, Z.X. Tang, H.Q. Zhang, B.J. Yan and Z.L. Ren \\ State Key Laboratory of Plant Genetics and Breeding, \\ Sichuan Agricultural University, Chengdu, Sichuan, China \\ Corresponding authors: B.J. Yan / Z.L. Ren \\ E-mail: yanbenju@sicau.edu.cn / renzllab@sicau.edu.cn
}

Genet. Mol. Res. 12 (2): 1740-1751 (2013)

Received June 1, 2012

Accepted March 6, 2013

Published May 21, 2013

DOI http://dx.doi.org/10.4238/2013.May.21.5

\begin{abstract}
Humid rain-fed agriculture is a special environment for wheat (Triticum aestivum) culture that tends to negatively affect wheat yield and quality. To identify quality characters of wheat in a humid environment, we conducted quality analysis and quantitative trait loci (QTL) detection in a recombinant inbred line whose parent had a high level of quality for several years. We found that high-quality wheat had less gluten content and lower protein content. Apparently, wheat quality and associated quantity traits were in a dynamic state of equilibrium. We detected 83 QTL for 10 wheat quality traits in this recombinant inbred line population. Nine QTL were detected in both evaluation years; Q.DT.scau-2A, linked to Xwmc522-2A, was detected at the same genetic location in both years. Other QTL for different traits were detected simultaneously in more than one location. Consequently, there appeared to be pleiotropic genes that control wheat quality. Based on previous studies and our research on QTL analysis of grain protein content, we conclude that there must be one or more genes for grain protein content on chromosome $6 \mathrm{~B}$, whose expression was little affected by environment. We constructed a consensus map and
\end{abstract}


projected the QTL on it. It was useful for choosing optimal markers for marker-assisted breeding and map-based cloning.

Key words: Wheat; Quality; Humid; Rain-fed agriculture; QTL; Consensus map

\section{INTRODUCTION}

Sichuan Basin, in southwest China, has many overcast, rainy days and high average annual air humidity. The crop grows under a condition of humid rain-fed subsistence agriculture, and the average annual rainfall is about $1000 \mathrm{~mm}$. For example, the rainfall averaged $1117.2 \mathrm{~mm}(1996)$ and $1117.6 \mathrm{~mm}(1988)$ per year in the Qionglai District (latitude $30^{\circ} 25^{\prime} \mathrm{N}$, longitude $103^{\circ} 28^{\prime} \mathrm{E}$, and altitude $493.3 \mathrm{~m}$ ), Chengdu, Sichuan, China (http://number.cnki.net/ cyfd/index.aspx). The wheat needs few or no supplementary irrigation during the entire process of growth. This particular climate offers many advantages, such as low cost, dependable crop, easy management, and lower labor requirements, among others. However, it also has disadvantages. Plant diseases and insect pests such as powdery mildew, stripe rust, gibberellic disease, and aphids increase, thereby decreasing yield. Meanwhile, end-use quality is decreased by pre-harvest sprouting (PHS). The development of high-yielding varieties with good end-use quality is a major focus in wheat breeding programs (Ren et al., 2010), especially for wheat grown in humid rain-fed agriculture.

Generally speaking, good cooking quality is related to high or intermediate protein content and high gluten quality (D'Egidio et al., 1990; Blanco et al., 2006). In bread wheat, protein content correlates with bread volume (Finney and Barrimore, 1948). Thus, abundant molecular research has been carried out to understand thoroughly the relationship between wheat quality and its regulating genes. Arbelbide and Bernardo (2006) detected 4 quantitative trait loci (QTL) for dough strength on chromosomes 1A, 1B, 1D, and 5B. Huang et al. (2006) found 3 QTL for mixing development time on chromosomes 1B, 1D, and 3B and 3 QTL for sodium dodecyl sulfate sedimentation volume (SV) on 1B, 2D, and 5D. Numerous studies on milling yield, dough rheology, and baking quality of wheat have been performed (Law et al., 2005; Kunert et al., 2007). Kuchel et al. (2006) mapped QTL for dough rheological traits on chromosomes $1 \mathrm{~A}$ and $1 \mathrm{~B}$, dough strength on chromosome $2 \mathrm{~A}$, and loaf volume on chromosome 3A.

Although many studies have been carried on wheat quality, few similar studies in humid rain-fed agriculture have been carried out. In general, PHS due mainly to early breakage of seed dormancy occurred more easily when plants were grown in wet weather for a long time during maturity and harvest (Liu et al., 2008). PHS lowers wheat yield and negatively affects the end-use quality of wheat products (Liu et al., 2008). Effective ways to minimize the quality reduction caused by PHS are to breed and grow cultivars with delayed germination time and reduced germination rate (Liu et al., 2008).

Wheat quality traits are expressed as quantitative traits that are forcefully influenced by environments or mutual effects between genotype and environment. In humid rain-fed agriculture, humidity is a major character. So wheat has corresponding quality characters in this special humid environment. In this research, we used a hexaploid wheat population of a R97 x R146 recombinant inbred line (RIL) as our study material and well-understood wheat 
quality traits in the environment of humid rain-fed agriculture at the level of physicochemical characteristics and molecular biology.

\section{MATERIAL AND METHODS}

\section{Genetic material}

A population of a $103 \mathrm{~F}_{9-10}$ RIL was constructed through single-seed descent from a cross between R146 as the female and R97 as the male. R146 is a line of resistant PHS wheat grown in southwest China. It has shown a high level of gluten quality and dough rheological characteristics over years.

The RIL and its parents were planted with 2 replications in Qionglai District (altitude $30^{\circ} 25^{\prime} \mathrm{N}$, longitude $103^{\circ} 28^{\prime} \mathrm{E}$, and altitude $493.3 \mathrm{~m}$ ), Chengdu, Sichuan, China, in 2008-2009 and 2009-2010. A plot with 2 rows was $3 \mathrm{~m}$ long and $25 \mathrm{~cm}$ apart, and 90 seeds were sowed in each row. The field management followed standard agricultural practice. Each plot was harvested by hand as soon as more than $70 \%$ of the plants reached maturity. The harvested seeds were sun-baked and stored in a ventilated room.

The whole wheat was milled (FOSS 1093 Cyclotec Sample Mill, Sweden) with a 0.5$\mathrm{mm}$ screen. The flour was milled by Laboratory Mill (Brabender Measurement and Control Systems, Germany). The wet gluten content (WGC) and gluten index (GI) were determined with a Glutenmatic 2200 (Perten, Sweden). Gluten protein content (GPC) was determined using a distillation unit B-324 (Buchi, Sweden). Farinograph quality number (FQN) was detected with a Farinograph-E (Brabender, Germany). SV was measured according to a procedure described by Dexter et al. (1980), and falling number (FN) was tested with a Perten 1700 (Sweden).

\section{Statistical analyses}

Statistical analyses of wheat quality traits were carried out on the mean of 4 replications using PASW Statistics 18.0 [http://www.umass.edu/statdata/ software/ news/spss/ (accessed August 7, 2012)]. Statistical significance between the parents was evaluated with the Student $t$-test. The correlation coefficient was calculated using Pearson's correlation. Significant differences were determined with a two-tailed test. The coefficient of variation $(\mathrm{CV})$ was calculated on the mean and standard deviation based on 4 replications.

\section{Map construction and QTL detection}

Leaves were harvested at the 3-leaf stage, and DNA was isolated from leaf tissue using the CTAB method (Saghai-Maroof et al., 1984). The simple-sequence repeat (SSR) primer pairs of XWMC were catalogued in the GrainGenes database [http://wheat.pw.usda.gov/cgibin/graingenes/browse.cgi?Class=marker (accessed August 8, 2012)]. SSR analysis was implemented following procedures published elsewhere (Senior and Heun, 1993; Liu et al., 2008), and a genetic linkage map was composed using MAPMAKER/EXP 3.0b (Lincoln et al., 1993).

WinQTLCart 2.5 [http://statgen.ncsu.edu/qtlcart/WQTLCart.htm (accessed August 8, 2012)] was used to perform composite interval mapping based on model 6 . The genome scan was accomplished via composite interval mapping using a backward regression method with 
a 10-cM window size. Permutation tests were carried out with 1000 repetitions at a $1-\mathrm{cM}$ walk speed and significance level of 0.05 .

\section{Construction of the new consensus map and QTL projection}

Wheat mapping data of microsatellite markers Xwmc, Xgwm, and Xbarc from 3 sets of mapping data (Somers et al., 2004; Quarrie et al., 2005; Xue et al., 2008) were used for consensus map construction (Table 1). The 3 high-density genetic maps covered 3522, 4223.1, and $2569 \mathrm{cM}$ and comprised 567, 887, and 1235 markers. The average interval distance ranged from 2.2 to $6.2 \mathrm{cM}$. Two of the maps were doubled-haploid population and RIL population, respectively. The third map of Somers et al. (2004) was constructed by joining 4 independent genetic maps of bread wheat (3 doubled-haploid and 1 RIL).

\begin{tabular}{|c|c|c|c|c|c|c|c|c|c|}
\hline \multirow[t]{3}{*}{ Mapping population } & \multirow[t]{3}{*}{ Total No. of markers } & \multirow[t]{3}{*}{ Length of map (cM) } & \multicolumn{7}{|c|}{ Number of SSR markers } \\
\hline & & & \multicolumn{4}{|c|}{ Type of markers } & \multicolumn{3}{|c|}{ Common markers } \\
\hline & & & Xbarc & Xgwm & Xwmc & Total & $\mathrm{N}^{\mathrm{b}}=2$ & $\mathrm{~N}=3$ & Total \\
\hline Chinese Spring x SQ1 & 567 & 3522 & 46 & 90 & 86 & 222 & 94 & 83 & 177 \\
\hline Nanda2419 x Wangshuibai & 887 & 4223.1 & 95 & 131 & 194 & 420 & 170 & 83 & 253 \\
\hline Consensus map & 1235 & 2569 & 141 & 273 & 357 & 771 & 236 & 83 & 319 \\
\hline
\end{tabular}

bIndex common markers in $\mathrm{n}$ other populations.

Firstly, 3 linkage maps were constructed with microsatellite markers from 3 sets of mapping data independently by JoinMap ${ }^{\circledR} 4$ (Van Ooijen, 2006). At the population nodes, we excluded some individuals and loci with many missing observations (missing above 90 genotypes and 38 individuals) and also removed identical loci with a similarity value of 1.0 using the Exclude Identicals function. Trees groupings were obtained by calculating in tabsheets of groupings with the default settings. Groups were created using the grouping tree. Finally, groups of the same chromosome in independent populations were combined into integrated groups, which constructed the new consensus map.

QTL of our mapping experiment were projected on the consensus map with BioMercator 2.1 (Arcade et al., 2004). The major projection procedure was executed as described by Chardon et al. (2004). First, the output QTL from WinQTLCart, consensus map constructed by JoinMap and our map constructed by MapMaker were all converted to text file for BioMercator input. Second, 3 text files of maps were imported into BioMercator, then the QTL file was added to our map. Finally, our map with QTL was projected onto the consensus map.

\section{RESULTS}

\section{Analysis of quality traits in the RIL population and parents}

All of the traits displayed genetic difference between the 2 parents to some extent. GI, FN, SV, development time (DT), stability time (ST), and FQN in particular showed significant differences based on a $t$-test (Table 2). For all the quality traits, the parent R146 had values higher than those of R97, and most traits reached greatly significant difference $(\mathrm{P}<0.01)$. The 
mean of all the traits in the RIL was between the values determined for the 2 parents except the mean of GPC, which was higher than the value in both parents. All the traits showed various degrees of transgressive segregation, and GI, FN, and FQN had higher standard deviation and $\mathrm{CV}(>12)$. At the same time, the traits demonstrated greatly significant differences between parents. Therefore, the RIL population was suitable for detecting QTL of quality traits.

\begin{tabular}{|c|c|c|c|c|c|c|c|}
\hline \multirow[t]{2}{*}{ Traits } & \multicolumn{5}{|c|}{ RIL population } & \multicolumn{2}{|c|}{ Parental lines } \\
\hline & Mean (\%) & $\operatorname{Min}(\%)$ & $\operatorname{Max}(\%)$ & SD & $\mathrm{CV}$ & R97 & R146 \\
\hline $\mathrm{GI}^{* *}$ & 70.1 & 4.8 & 98.7 & 22.9 & 32.7 & 57.2 & 95.4 \\
\hline WGC & 28.3 & 23.8 & 40.0 & 3.0 & 10.5 & 27.7 & 28.6 \\
\hline DGC & 9.1 & 7.8 & 11.9 & 0.9 & 9.9 & 9.0 & 9.3 \\
\hline WB & 19.1 & 15.8 & 28.1 & 2.1 & 11.0 & 18.7 & 19.3 \\
\hline $\mathrm{FN}^{* *}$ & 309.3 & 153.5 & 397.5 & 38.4 & 12.4 & 261.3 & 366.0 \\
\hline $\mathrm{SV}^{* *}$ & 8.3 & 5.2 & 12.0 & 1.5 & 17.6 & 6.9 & 10.8 \\
\hline $\mathrm{DT}^{* *}$ & 4.6 & 1.3 & 18.5 & 2.8 & 60.9 & 2.6 & 7.3 \\
\hline $\mathrm{ST}^{* *}$ & 8.1 & 1.2 & 19.1 & 4.6 & 57.4 & 5.4 & 13.7 \\
\hline $\mathrm{FQN} * *$ & 84.8 & 26.0 & 203.0 & 44.0 & 51.9 & 56.0 & 142.3 \\
\hline GPC & 13.2 & 10.5 & 17.5 & 1.1 & 8.5 & 12.2 & 12.8 \\
\hline
\end{tabular}

$\mathrm{SD}=$ standard deviation; $\mathrm{CV}=$ coefficient of variation; $\mathrm{GI}=$ gluten index $; \mathrm{WGC}=$ wet gluten content; $\mathrm{DGC}=$ dry gluten content; $\mathrm{WB}=$ wheat bran; $\mathrm{FN}=$ falling number; $\mathrm{SV}=$ sedimentation volume; $\mathrm{DT}=$ development time; $\mathrm{ST}=$ stability time; FQN $=$ farinograph quality number; GPC $=$ gluten protein content. ${ }^{*}$ Indexed significant differences $(\mathrm{P}<0.01)$.

\section{Genetic correlations between wheat quality traits}

To comprehend the interrelationship among the traits we detected, all data from the wheat RIL population were analyzed with Pearson's linear correlation. The genetic correlation coefficients between traits are shown in Table 3. All traits showed different degrees of correlation. GI was significantly negatively correlated with WGC $(\mathrm{r}=-0.490, \mathrm{P}=0.000)$, dry gluten content (DGC; $\mathrm{r}=-0.437, \mathrm{P}=0.000$ ), and wheat bran (WB; $\mathrm{r}=-0.503, \mathrm{P}=0.000)$. WGC, DGC, and WB were strongly positively correlated with one another. SV was significantly positively correlated with GI $(\mathrm{r}=0.384, \mathrm{P}=0.000)$, WGC $(\mathrm{r}=0.390, \mathrm{P}=0.000)$, DGC $(\mathrm{r}=0.407$, $\mathrm{P}=0.000)$, and $\mathrm{WB}(\mathrm{r}=0.374, \mathrm{P}=0.000)$. GPC was strong positive correlated with WGC $(\mathrm{r}=$ $0.709, \mathrm{P}=0.000)$, DGC $(\mathrm{r}=0.667, \mathrm{P}=0.000)$, WB $(\mathrm{r}=0.712, \mathrm{P}=0.000)$, and $\mathrm{SV}(\mathrm{r}=0.276$, $\mathrm{P}=0.006)$, and strong negative correlated with $\mathrm{GI}(\mathrm{r}=-0.285, \mathrm{P}=0.004)$. GI was correlated or strongly correlated with dough rheological characteristics of DT $(\mathrm{r}=0.201, \mathrm{P}=0.047)$, ST $(\mathrm{r}=0.678, \mathrm{P}=0.000)$, and $\mathrm{FQN}(\mathrm{r}=0.480, \mathrm{P}=0.000)$. FN was correlated with DT $(\mathrm{r}=0.243$, $\mathrm{P}=0.016)$ and $\mathrm{FQN}(\mathrm{r}=0.201, \mathrm{P}=0.047) . \mathrm{FQN}$ was negative correlated with $\mathrm{WB}(\mathrm{r}=-0.202$, $\mathrm{P}=0.046)$. ST was strong negative correlated with WGC $(\mathrm{r}=-0.394, \mathrm{P}=0.000)$, DGC $(\mathrm{r}=$ $-0.342, \mathrm{P}=0.001)$, and WB $(\mathrm{r}=-0.408, \mathrm{P}=0.000)$. We found that FQN, ST, FN, and GI were all negative correlated with GPC, WGC, and DGC. The increased quality may have been usually accompanied by decreased content of quantity traits (e.g., gluten content and GPC).

\section{QTL analysis for grain quality traits}

Wheat quality traits were quantity traits. Genotype-environment interactions on QTL were embodied in the wheat development. To understand the quality trait variation in multiple 
environments, the nature of genetic variation in major wheat quality traits was investigated in an RIL population by mapping QTL for 2 years.

Table 3. Genetic correlation between wheat quality traits in wheat recombinant inbred lines (RIL) and their parents.

\begin{tabular}{|c|c|c|c|c|c|c|c|c|c|}
\hline & WGC & DGC & WB & FN & SV & DT & ST & FQN & GPC \\
\hline GI & $-0.491 * *$ & $-0.437 * *$ & $-0.503 * *$ & -0.051 & $0.384 * *$ & $0.201 *$ & $0.678 * *$ & $0.480 * *$ & $-0.285 * *$ \\
\hline WGC & & $0.965 * *$ & $0.994 * *$ & -0.070 & $0.390 * *$ & 0.001 & $-0.395 * *$ & -0.191 & $0.709 * *$ \\
\hline DGC & & & $0.930 * *$ & -0.127 & $0.408 * *$ & 0.007 & $-0.343 * *$ & -0.155 & $0.668 * *$ \\
\hline WB & & & & -0.044 & $0.374 * *$ & -0.02 & $-0.409 * *$ & $-0.202 *$ & $0.712 * *$ \\
\hline $\mathrm{FN}$ & & & & & 0.107 & $0.243^{*}$ & 0.070 & $0.201 *$ & -0.053 \\
\hline SV & & & & & & 0.065 & 0.158 & 0.179 & $0.276^{* *}$ \\
\hline DT & & & & & & & $0.636 * *$ & $0.816^{* *}$ & 0.045 \\
\hline ST & & & & & & & & $0.882 * *$ & $-0.273 * *$ \\
\hline FQN & & & & & & & & & -0.119 \\
\hline
\end{tabular}

****Indicate significance at $\mathrm{P}<0.05$ and $\mathrm{P}<0.01$, respectively. For abbreviations, see legend to Table 2.

\section{Dough rheological characteristics}

Ten QTL for DT and FQN were detected in 2008 and 2009 (Table 4). Five and 1 stable QTL were detected in both years for DT and FQN, respectively. Two QTL (Q.DT.scau-1A.1 and Q.DT.scau-1A.2) of DT were both linked to the molecular marker xwmc611-1A. Q.DT.scau-4D linked to xwmc473-4D had a higher LOD score and phenotypic variation (LOD $>5.4, \mathrm{R}^{2}>5.7$ ) and displayed stability in both years. We found that Q.DT.scau-7D and Q.FQN-scau-7D were both linked to the same marker, xwmc634-7D, and had similar genetic locations. In the QTL analysis for dough rheological characteristics, we detected only 2 QTL of ST at a time.

\begin{tabular}{|c|c|c|c|c|c|c|c|c|c|c|}
\hline \multirow[t]{2}{*}{ Traits } & \multirow[t]{2}{*}{ QTL $^{\mathrm{a}}$} & \multirow[t]{2}{*}{ Marker $^{\mathrm{b}}$} & \multirow[t]{2}{*}{ Position } & \multicolumn{2}{|c|}{$2008 \sim 2009$} & \multirow[t]{2}{*}{$\mathrm{R}^{2}$} & \multirow[t]{2}{*}{ Position } & \multicolumn{2}{|c|}{$2009 \sim 2010$} & \multirow[t]{2}{*}{$\mathrm{R}^{2}$} \\
\hline & & & & $\begin{array}{l}\text { LOD } \\
\text { score }\end{array}$ & $\begin{array}{c}\text { Additive } \\
\text { effect }\end{array}$ & & & $\begin{array}{l}\text { LOD } \\
\text { score }\end{array}$ & $\begin{array}{l}\text { Additive } \\
\text { effect }\end{array}$ & \\
\hline \multirow[t]{8}{*}{ DT } & Q.DT.scau-1A.1 & Xwmc611-1A & 2.9 & 7.7 & -0.2 & $>0.0$ & 2.7 & 8.0 & -0.2 & 0.3 \\
\hline & Q.DT.scau-1A.2 & Xwmc611-1A & 16.4 & 7.6 & -0.1 & $>0.0$ & 17.2 & 7.9 & -0.2 & $>0.0$ \\
\hline & Q.DT.scau-1A.3 & Xwmc329-1A & & & & & 1.6 & 6.9 & -0.1 & $>0.0$ \\
\hline & Q.DT.scau-1B & Xwmc419-1B & 56.2 & 6.3 & -0.6 & 4.6 & 54.7 & 6.8 & -0.3 & 0.8 \\
\hline & Q.DT.scau-1D & Xwmc222-1D & & & & & 1.0 & 7.1 & $>0.0$ & 0.1 \\
\hline & Q.DT.scau-2A & Xwmc522-2A & 16.1 & 6.5 & 0.4 & 3.6 & 16.1 & 7.7 & 0.4 & 3.2 \\
\hline & Q.DT.scau-4D & Xwmc473-4D & 33.9 & 5.4 & -0.4 & 5.7 & 34.2 & 5.6 & -0.3 & 5.8 \\
\hline & Q.DT.scau-7D & Xwmc634-7D & 66.7 & 7.3 & 0.6 & 3.5 & & & & \\
\hline \multirow[t]{2}{*}{ FQN } & Q.FQN.scau-4A & Xwmc161-4A & 4.5 & 4.4 & -5.2 & 0.7 & & & & \\
\hline & Q.FQN.scau-7D & Xwmc634-7D & 64.7 & 6.5 & 2.1 & 4.8 & 65.0 & 6.6 & 5.8 & 1.3 \\
\hline
\end{tabular}

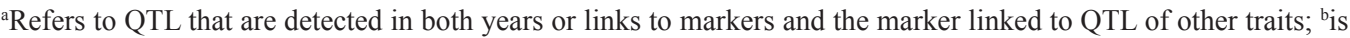
for the marker that is nearest to corresponding QTL. For abbreviations, see legend to Table 2.

\section{Wheat protein and its correlated traits}

As shown in Table 5, 3 stable QTL for 2 traits (WB and GPC) were found through QTL analysis. Q.GPC.scau-6B linked to marker xwmc419-6B was the only stable QTL for GPC. Three QTL (Q.GPC.scau-1B, Q.WB.scau-1B, and Q.WGC.scau-1B) were found all linked to the same marker, xwmc728-1B, at similar genetic locations. Q.WB.scau-1B was 
detected during both years. A stable QTL of Q.WB.scau-7D.1 linked to xwmc634-7D was detected at the genetic location of 66.1 and $66.3 \mathrm{cM}$ for 2 years. At a similar genetic location, we also detected 2 QTL for DT and FQN (see Table 4).

\begin{tabular}{|c|c|c|c|c|c|c|c|c|c|c|}
\hline \multirow[t]{2}{*}{ Traits } & \multirow[t]{2}{*}{ QTL $^{\mathrm{a}}$} & \multirow[t]{2}{*}{ Marker $^{b}$} & \multirow[t]{2}{*}{ Position } & \multicolumn{2}{|c|}{ 2008 2009 } & \multirow[t]{2}{*}{$\mathrm{R}^{2}$} & \multirow[t]{2}{*}{ Position } & \multicolumn{2}{|c|}{ 2009 2010 } & \multirow[t]{2}{*}{$\mathrm{R}^{2}$} \\
\hline & & & & $\begin{array}{l}\text { LOD } \\
\text { score }\end{array}$ & $\begin{array}{l}\text { Additive } \\
\text { effect }\end{array}$ & & & $\begin{array}{l}\text { LOD } \\
\text { score }\end{array}$ & $\begin{array}{l}\text { Additive } \\
\text { effect }\end{array}$ & \\
\hline \multirow[t]{7}{*}{ GPC } & Q.GPC.scau-1A.1 & Xwmc329-1A & 1.6 & 4.6 & 0.1 & $>0.0$ & \multirow{4}{*}{2.7} & \multirow{3}{*}{3.3} & \multirow{3}{*}{$>0.0$} & \multirow{3}{*}{0.2} \\
\hline & Q.GPC.scau-1A.2 & Xwmc611-1A & & & & & & & & \\
\hline & Q.GPC.scau-1B & Xwmc728-1B & 77.7 & 3.5 & $>0.0$ & 0.4 & & & & \\
\hline & Q.GPC.scau-1D & Xwmc222-1D & 1.0 & 4.8 & 0.1 & 0.5 & & & & \\
\hline & Q.GPC.scau-2A & Xwmc522-2A & & & & & \multirow[t]{2}{*}{16.1} & \multirow[t]{2}{*}{3.7} & \multirow[t]{2}{*}{-0.1} & \multirow[t]{2}{*}{0.1} \\
\hline & Q.GPC.scau-4A & Xwmc161-4A & 5.5 & 4.0 & $>0.0$ & 0.5 & & & & \\
\hline & Q.GPC.scau-6B & Xwmc419-6B & 65.7 & 3.6 & $>0.0$ & 0.1 & 66.4 & 3.4 & $>0.0$ & 0.6 \\
\hline \multirow[t]{5}{*}{ WB } & Q.WB.scau-1B & Xwmc728-1B & 77.0 & 4.3 & 0.2 & 1.4 & 77.2 & 3.4 & 0.2 & 1.0 \\
\hline & Q.WB.scau-1D & Xwmc222-1D & & & & & \multirow[t]{2}{*}{1.0} & \multirow[t]{2}{*}{4.2} & \multirow[t]{2}{*}{-0.2} & \multirow[t]{2}{*}{0.7} \\
\hline & Q.WB.scau-6B & Xwmc388a & 47.1 & 3.0 & $>0.0$ & 0.7 & & & & \\
\hline & Q.WB.scau-7D.1 & Xwmc634-7D & 66.1 & 5.3 & 0.3 & $>0.0$ & 66.3 & 3.0 & 0.1 & 0.1 \\
\hline & Q.WB.scau-7D.2 & Xwmc473c & & & & & 1.0 & 4.6 & 0.4 & 1.8 \\
\hline \multirow[t]{4}{*}{ WGC } & Q.WGC.scau-1B & Xwmc728-1B & 78.5 & 5.4 & 0.2 & 1.1 & \multirow{3}{*}{1.0} & \multirow{3}{*}{3.1} & & \multirow{3}{*}{2.0} \\
\hline & Q.WGC.scau-1D & Xwmc222-1D & & & & & & & \multirow[t]{2}{*}{0.5} & \\
\hline & Q.WGC.scau-6B & Xwmc388a & 46.5 & 4.2 & $>0.0$ & 1.3 & & & & \\
\hline & Q.WGC.scau-7D & Xwmc $473 c$ & & & & & 1.0 & 4.1 & 0.6 & 2.0 \\
\hline
\end{tabular}

${ }^{a}$ Refers to QTL that are detected in both years or links to markers and the marker linked to QTL of other traits; ${ }^{\text {bis }}$ for the marker that is nearest to corresponding QTL. For abbreviations, see legend to Table 2.

Salih and Adelson (2009) stated that genes with similar functions may be grouped in specific locales and can contribute to QTL traits. In our study, QTL of some traits were detected in the same or similar genetic locations (Table 6). Q.DT.scau-1D, Q.GPC.scau-1D, Q.WB.scau1D, and Q.WGC.scau-1D were all linked to molecule marker xwmc222-1D at the $1 \mathrm{cM}$ genetic position. In 2009, QTL for trait pairs WGC and WB and DT and GPC were located at the genetic position 1 (linked to xwmc473c, 7D) and $2.7 \mathrm{cM}$ (linked to xwmc611-1A, 1A), respectively. We found that 4 locations on chromosome $1 \mathrm{~A}$ (xwmc329-1A $1.6 \mathrm{cM}$ and xwmc611-1A $2.7 \mathrm{cM}$ ), 2A (xwmc522-2A 16.1 cM), and 1D (xwmc222-1D $1 \mathrm{cM}$ ) harbored QTL of DT and GPC. These coincidences may be due to pleiotropy or genetic linkage (Heidari et al., 2011).

\section{Consensus map and QTL projection}

Two hundred and fifty and 83 markers were shared by 2 and 3 individual maps that were used for construction of the new consensus map (Table 1). We checked the 3 map data with JoinMap and excluded 40 markers and 35 individuals, which had many missing observations. Finally, this consensus map comprised 617 markers, including 119 Xbarc, 187 Xgwm and $311 \mathrm{Xwmc}$. All these markers were distributed on 21 linkage groups covering $1881.1 \mathrm{cM}$ with an average interval distance of $3.0 \mathrm{cM}$ (Figure S1). On the consensus map, only 4 linkage groups $(1 \mathrm{D}, 4 \mathrm{D}, 5 \mathrm{D}$, and $6 \mathrm{D})$ had the lower marker density and the lowest was $8.3 \mathrm{cM}$ per marker in 1D, and there were no effective fixed orders in fixed-order file. Moreover, there were 32 common markers between our map data and the consensus map. It was feasible to project our map and QTL on to the consensus map (Figure 1). 
Table 6. QTL with the same or close location of genetic position in combined analysis.

\begin{tabular}{|c|c|c|c|c|c|c|}
\hline Traits & $\mathrm{QTL}^{\mathrm{a}}$ & Marker $^{b}$ & Position & LOD score & Additive effect & $\mathrm{R}^{2}$ \\
\hline FQN & Q.FQN.scau-4A & Xwmc161-4A & 4.5 & 4.4 & -5.2 & 0.7 \\
\hline GPC & Q.GPC.scau-4A & Xwmc161-4A & 5.5 & 4.0 & $>0.0$ & 0.5 \\
\hline DT & Q.DT.scau-1D & Xwmc222-1D & 1.0 & 7.1 & $>0.0$ & 0.1 \\
\hline GPC & Q.GPC.scau-1D & Xwmc222-1D & 1.0 & 4.8 & 0.1 & 0.5 \\
\hline WB & Q.WB.scau-1D & Xwmc222-1D & 1.0 & 4.2 & -0.2 & 0.7 \\
\hline WGC & Q.WGC.scau-1D & Xwmc222-1D & 1.0 & 3.1 & 0.5 & 2.0 \\
\hline DT & Q.DT.scau-1A.3 & Xwmc329-1A & 1.6 & 6.9 & -0.1 & $>0.0$ \\
\hline GPC & Q.GPC.scau-1A.1 & Xwmc329-1A & 1.6 & 4.6 & 0.1 & $>0.0$ \\
\hline WB & Q.WB.scau-6B & Xwmc388a & 47.1 & 3.0 & $>0.0$ & 0.7 \\
\hline WGC & Q.WGC.scau-6B & Xwmc388a & 46.5 & 4.2 & $>0.0$ & 1.3 \\
\hline WB & Q.WB.scau-7D.2 & Xwmc473c & 1.0 & 4.6 & 0.4 & 1.8 \\
\hline WGC & Q.WGC.scau-7D & Xwmc473c & 1.0 & 4.1 & 0.6 & 2.0 \\
\hline DT & Q.DT.scau-2A & Xwmc522-2A & 16.1 & 7.7 & 0.4 & 3.2 \\
\hline GPC & Q.GPC.scau-2A & Xwmc522-2A & 16.1 & 3.7 & -0.1 & 0.1 \\
\hline DT & Q.DT.scau-1A.1 & Xwmc611-1A & 2.7 & 8.0 & -0.2 & 0.3 \\
\hline GPC & Q.GPC.scau-1A.2 & Xwmc611-1A & 2.7 & 3.3 & $>0.0$ & 0.2 \\
\hline FQN & Q.FQN.scau-7D & Xwmc634-7D & 65.0 & 6.6 & 5.8 & 1.3 \\
\hline WB & Q.WB.scau-7D.1 & Xwmc634-7D & 66.3 & 3.0 & 0.1 & 0.1 \\
\hline DT & Q.DT.scau-7D & Xwmc634-7D & 66.7 & 7.3 & 0.6 & 3.5 \\
\hline GPC & Q.GPC.scau-1B & Xwmc728-1B & 77.7 & 3.5 & $>0.0$ & 0.4 \\
\hline WB & Q.WB.scau-1B & Xwmc728-1B & 77.2 & 3.4 & 0.2 & 1.0 \\
\hline WGC & Q.WGC.scau-1B & Xwmc728-1B & 78.5 & 5.4 & 0.2 & 1.1 \\
\hline
\end{tabular}

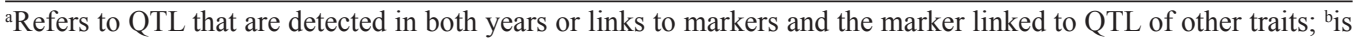
for the marker that is nearest to corresponding QTL. For abbreviations, see legend to Table 2.
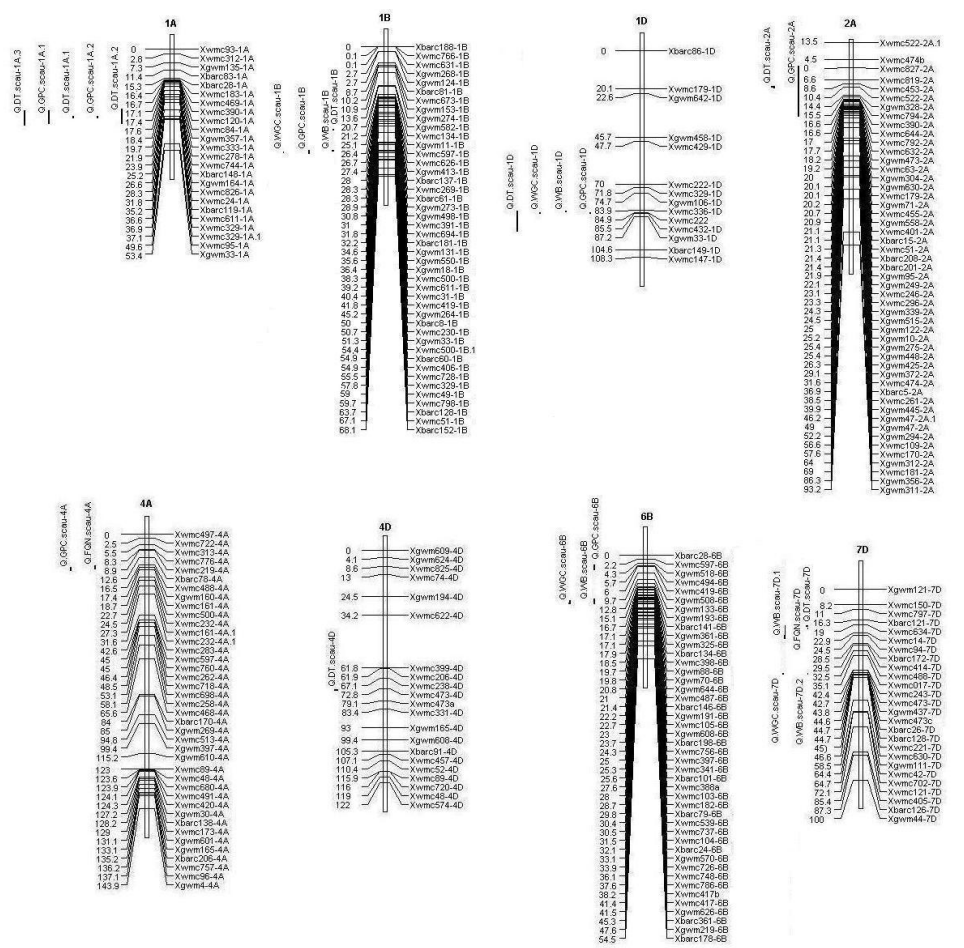

Figure 1. Positions of QTL associated with major quality traits of wheat in the R146 x R97 RIL population. 


\section{DISCUSSION}

Gluten strength is a function of both protein concentration and protein composition (Guttieri et al., 2001). Gluten composed of glutenin and gliadin proteins is one of the major determinants of the elasticity of dough; it forms a network in dough and confers viscoelasticity, which are necessary to produce high-quality bread (Yahata et al., 2006). GI is expressed as the ratio of wet gluten remaining on a sieve after centrifuging to the total wet gluten weight. This index has become the standard procedure for evaluating gluten strength and correlates well with sodium dodecyl sulfate (Cubadda et al., 1992). Generally speaking, the higher the GI, the higher the gluten quality (Hu et al., 2004) and dough rheological characteristics. In our present study (see Table 3), GI was significantly positive correlated with $\mathrm{SV}(\mathrm{r}=0.384, \mathrm{P}=0.000)$ and positive correlated or strong positive correlated with the dough rheological characteristics DT $(r=0.201, P=0.047)$, ST $(r=0.678, P=0.000)$, and FQN $(r=0.480, P=0.000)$. We also found that GI was strongly negatively correlated with WGC $(\mathrm{r}=-0.490, \mathrm{P}=0.000), \mathrm{DGC}(\mathrm{r}=$ $-0.437, \mathrm{P}=0.000)$, WB $(\mathrm{r}=-0.503, \mathrm{P}=0.000)$, and $\mathrm{GPC}(\mathrm{r}=-0.285, \mathrm{P}=0.004)$. ST, a dough rheological characteristic, was strong correlated with GI and significantly negative correlated with gluten characters (WGC, DGC, WB, and GPC). FQN was loosely negative correlated with WGC, DGC, and GPC. These correlations meant that high-quality wheat contained less gluten and had a lower GPC. In the QTL analysis, the QTL of quality (FQN and DT) and quantity (GPC) traits linked to these markers (red type) had the opposite additive effect (see Table 6). Hu and Shang (2007) also indicated that high-quality wheat varieties contain less wet gluten but have a higher GI. We believed that wheat quality and associated quantity trait content was in a dynamic state of equilibrium, and the increased quality was usually accompanied by decreased quantity traits (e.g., gluten content and GPC) based on the data.

Among 83 QTL for 10 traits in this study, 9 QTL were detected across 2 environments (years): 5 for DT, 1 for FQN, 2 for WB, and 1 for GPC. GPC, DT, and FQN were important factors in wheat end-using quality. It had generally been believed that stable QTL that expressed across different environments had more potential to be used in marker-assisted breeding (MAB) and further research (Wei et al., 2009). Hence, we were able to find more appropriate markers for these important traits based on the new consensus map.

Three stable QTL for the dough rheological character DT were located on chromosome 1A (Q.DT.scau-1A.1 and Q.DT.scau-1A.2, both linked to xwmc611-1A) and 1B (Q.DT. scau-1B, linked to xwmc419-1B). Previous research (Campbell et al., 2001; Kuchel et al., 2006; Nelson et al., 2006) has also reported additional QTL for dough rheological traits on chromosomes 1A and 1B. These dough rheological traits may be influenced by their placement in specific regions of chromosomes 1A and 1B (Nelson et al., 2006). A number of reports have identified GPC QTL on various chromosomes, and they have all detected at least one GPC QTL on chromosome 6B (Joppa and Cantrell, 1990; Blanco et al., 1996; Steiger et al., 1996; Olmos et al., 2003; Prasad et al., 2003; Distelfeld et al., 2004; Turner et al., 2004). Prasad et al. (2003) identified 2 GPC QTL on 6Bs, one of which linked to marker xgwm1336B. On chromosomes 6B and 7B, we also detected 2 GPC QTL linked to xwmc419-6B (see Table 5) and xwmc232-7B (data not shown), respectively. Two markers of xgwm133-6B and xwmc419-6B had close genetic distance in our consensus map (see Figure 1). Olmos et al. (2003) also found 1 GPC QTL with similar genetic distance on chromosome arm 6Bs. So, 1 or more genes for GPC that can stably express with smaller environmental impact must be pres- 
ent on chromosome 6B. We believe that some (or specific) chromosomes may harbor specific regions or multi-genes (but only one or few genes can express) for 1 trait.

Genes with similar functions may be grouped in specific locales and could contribute to QTL traits (Salih and Adelson, 2009). In the study of gene clusters (see Table 6), we found that QTL for more traits were detected in more than 1 genetic location simultaneously. Therefore, these locations must contain genes with pleiotropy, and these genes interweave a web of wheat quality. The pleiotropy may strongly constrain possible mutational avenues because of the interwoven web of genetic and physiological interactions that were involved in development and function (Hodgkin, 1998). In wheat breeding, wheat quality traits were almost quantity traits. Genetically speaking, all quality traits had a definite relationship with one another. Wheat quality traits controlled by more pleiotropic genes may conceivably be involved in wheat quality breeding. The pleiotropic genes have constrained possible mutation over the long term of wheat breeding, and hence have slowed wheat quality breeding.

Our dense genetic map was very useful for MAB. It was furthermore important for map-based cloning and genome sequencing projects (Varshney et al., 2006, 2007). To date, a large number of markers have been developed and mapped in populations. However, these markers diffused in different populations, so they cannot offer additional information like markers mapped in a single mapping population. Varshney et al. (2007) described an alternative way to prepare a dense genetic map that combines various genetic maps by exploiting common markers. The density of the genetic map in our research was enhanced greatly through consensus map construction and QTL projecting. Meanwhile, the reflection of QTL on a consensus map provided a convenient way to choose optimal markers for MAB and map-based cloning.

\section{ACKNOWLEDGMENTS}

Research supported by the National Natural Science Foundation of China (\#30730065) and the National 973 Wheat Breeding Program. We also thank Dr. Luo PeiGao for kindly offering the SSR marker.

\section{Supplementary material}

\section{REFERENCES}

Arbelbide M and Bernardo R (2006). Mixed-model QTL mapping for kernel hardness and dough strength in bread wheat. Theor. Appl. Genet. 112: 885-890.

Arcade A, Labourdette A, Falque M, Mangin B, et al. (2004). BioMercator: integrating genetic maps and QTL towards discovery of candidate genes. Bioinformatics 20: 2324-2326.

Blanco A, Giovanni C, Laddomada B and Sciancalepore A (1996). Quantitative trait loci influencing grain protein content in tetraploid wheats. Plant Breed. 115: 310-316.

Blanco A, Simeone R and Gadaleta A (2006). Detection of QTLs for grain protein content in durum wheat. Theor. Appl. Genet. 112: 1195-1204.

Campbell KG, Finney PL, Bergman CJ, Gualberto DG, et al. (2001). Quantitative trait loci associated with milling and baking quality in a soft $\mathrm{x}$ hard wheat cross. Crop Sci. 41: 1275-1285.

Chardon F, Virlon B, Moreau L, Falque M, et al. (2004). Genetic architecture of flowering time in maize as inferred from quantitative trait loci meta-analysis and synteny conservation with the rice genome. Genetics 168: 2169-2185.

Cubadda R, Carcea M and Pasqui LA (1992). Suitability of the gluten index method for assessing gluten strength in durum wheat and semolina. Cereal Foods World 37: 866-869.

D'egidio MG, Mariani BM, Nardi S, Novaro P, et al. (1990). Chemical and technological variables and their relationships: 
a predictive equation for pasta cooking quality. Cereal Chem. 67: 275-281.

Dexter JE, Matsuo RR, Kosmolak FG, Leisle D, et al. (1980). The suitability of the SDS-sedimentation test for assessing gluten strength in durum wheat. Can. J. Plant Sci. 60: 25-29.

Distelfeld A, Uauy C, Olmos S, Schlatter AR, et al. (2004). Microcolinearity between a 2-cM region encompassing the grain protein content locus $\mathrm{Gpc}-6 \mathrm{~B} 1$ on wheat chromosome $6 \mathrm{~B}$ and a $350-\mathrm{kb}$ region on rice chromosome 2. Funct. Integr. Genomics 4: 59-66.

Finney KF and Barrimore MA (1948). Loaf volume and protein content of hard winter and spring wheat. Cereal Chem. 25: 291-312.

Guttieri MJ, Bowen D, Gannon D, O’Brien K, et al. (2001). Solvent retention capacities of irrigated soft white spring wheat flours. Crop Sci. 41: 1054-1061.

Heidari B, Sayed-Tabatabaei BE, Saeidi G, Kearsey M, et al. (2011). Mapping QTL for grain yield, yield components, and spike features in a doubled haploid population of bread wheat. Genome 54: 517-527.

Hodgkin J (1998). Seven types of pleiotropy. Int. J. Dev. Biol. 42: 501-505.

Hu XZ and Shang YN (2007). A new testing method for vital gluten swelling index. J. Sci. Food Agric. 87: 1778-1782.

Hu XZ, Wei YM, Kovacs MIP and Wang C (2004). Swelling index of glutenin (SIG) related to protein quality, dough characters and noodle quality. Agric. Sci. China 3: 746-753.

Huang XQ, Cloutier S, Lycar L, Radovanovic N, et al. (2006). Molecular detection of QTLs for agronomic and quality traits in a doubled haploid population derived from two Canadian wheats (Triticum aestivum L.). Theor. Appl. Genet. 113: $753-766$.

Joppa LR and Cantrell RG (1990). Chromosomal location of genes for grain protein content of wild tetraploid wheat. Crop Sci. 30: 1059-1064.

Kuchel H, Langridge P, Mosionek L, Williams K, et al. (2006). The genetic control of milling yield, dough rheology and baking quality of wheat. Theor. Appl. Genet. 112: 1487-1495.

Kunert A, Naz AA, Dedeck O, Pillen K, et al. (2007). AB-QTL analysis in winter wheat: I. Synthetic hexaploid wheat (T. turgidum ssp. dicoccoides $\mathrm{x}$ T. tauschii) as a source of favourable alleles for milling and baking quality traits. Theor. Appl. Genet. 115: 683-695.

Law CN, Bhandari DG, Salmon SE, Greenwell PW, et al. (2005). Novel genes on chromosome 3A influencing breadmaking quality in wheat, including a new gene for loaf volume, Lvl 1. J. Cereal Sci. 41: 317-326.

Lincoln SE, Daly MJ and Lander ES (1993). Constructing Genetic Linkage Maps with MAPMAKER/EXP Version 3.0b. Whitehead Institute for Biomedical. 3rd edn. Research Technical Report, Cambridge.

Liu S, Cai S, Graybosch R, Chen C, et al. (2008). Quantitative trait loci for resistance to pre-harvest sprouting in US hard white winter wheat Rio Blanco. Theor. Appl. Genet. 117: 691-699.

Nelson JC, Andreescu C, Breseghello F, Finney PL, et al. (2006). Quantitative trait locus analysis of wheat quality traits. Euphytica 149: 145-159.

Olmos S, Distelfeld A, Chicaiza O, Schlatter AR, et al. (2003). Precise mapping of a locus affecting grain protein content in durum wheat. Theor. Appl. Genet. 107: 1243-1251.

Prasad M, Kumar N, Kulwal PL, Roder MS, et al. (2003). QTL analysis for grain protein content using SSR markers and validation studies using NILs in bread wheat. Theor. Appl. Genet. 106: 659-667.

Quarrie SA, Steed A, Calestani C, Semikhodskii A, et al. (2005). A high-density genetic map of hexaploid wheat (Triticum aestivum L.) from the cross Chinese Spring $\mathrm{x}$ SQ1 and its use to compare QTLs for grain yield across a range of environments. Theor. Appl. Genet. 110: 865-880.

Ren Z, Zhu H, Song H, Li S, et al. (2010). Wheat Breeding in Rain-Fed Agriculture. Science Press, Beijing.

Saghai-Maroof MA, Soliman KM, Jorgensen RA and Allard RW (1984). Ribosomal DNA spacer-length polymorphisms in barley: mendelian inheritance, chromosomal location, and population dynamics. Proc. Natl. Acad. Sci. U. S. A. 81: 8014-8018.

Salih H and Adelson DL (2009). QTL global meta-analysis: are trait determining genes clustered? BMC Genomics 10: 184.

Senior ML and Heun M (1993). Mapping maize microsatellites and polymerase chain reaction confirmation of the targeted repeats using a CT primer. Genome 36: 884-889.

Somers DJ, Isaac P and Edwards K (2004). A high-density microsatellite consensus map for bread wheat (Triticum aestivum L.). Theor. Appl. Genet. 109: 1105-1114.

Steiger DK, Elias EM and Cantrell RG (1996). Evaluation of lines derived from wild emmer chromosome substitutions: I. Quality traits. Crop Sci. 36: 223-227.

Turner AS, Bradburne RP, Fish L and Snape JW (2004). New quantitative trait loci influencing grain texture and protein content in bread wheat. J. Cereal Sci. 40: 51-60.

Van Ooijen JW (2006). JoinMap 4: Software for the Calculation of Genetic Linkage Maps in Experimental Populations 
(Kyazma BV, ed.). Wageningen, Netherlands.

Varshney RK, Hoisington DA and Tyagi AK (2006). Advances in cereal genomics and applications in crop breeding. Trends Biotechnol. 24: 490-499.

Varshney RK, Marcel TC, Ramsay L, Russell J, et al. (2007). A high density barley microsatellite consensus map with 775 SSR loci. Theor. Appl. Genet. 114: 1091-1103.

Wei M, Li X, Li J, Fu J, et al. (2009). QTL detection for stover yield and quality traits using two connected populations in high-oil maize. Plant Physiol. Biochem. 47: 886-894.

Xue S, Zhang Z, Lin F, Kong Z, et al. (2008). A high-density intervarietal map of the wheat genome enriched with markers derived from expressed sequence tags. Theor. Appl. Genet. 117: 181-189.

Yahata E, Maruyama-Funatsuki W, Nishio Z, Yamamoto Y, et al. (2006). Relationship between the dough quality and content of specific glutenin proteins in wheat mill streams, and its application to making flour suitable for instant Chinese noodles. Biosci. Biotechnol. Biochem. 70: 788-797. 